\title{
Gene Dropping Analysis of Ancestral Contributions and Allele Survival in Japanese Thoroughbred Population
}

\author{
Jun YAMASHITA ${ }^{1}$, Hironori OKI ${ }^{2}$, Telhisa HASEGAWA ${ }^{2}$, Takeshi HONDA ${ }^{3}$ and \\ Tetsuro NOMURA ${ }^{4 *}$ \\ ${ }^{1}$ Department of Biotechnology, Faculty of Engineering, Kyoto Sangyo University, Kita-ku, Kyoto 603-8555, \\ ${ }^{2}$ Equine Research Institute, Japan Racing Association, 321-4 Tokami-cho, Utsunomiya, Tochigi 320-0856, \\ ${ }^{3}$ Food Resources Education and Research Center, Graduate School of Agricultural Science, Kobe University, \\ 1348 Uzurano-cho, Kasai, Hyogo 675-2103, ${ }^{4}$ Department of Bioresource and Environmental Sciences, Faculty \\ of Life Sciences, Kyoto Sangyo University, Kita-ku, Kyoto 603-8555, Japan
}

Genetic contributions of nine historically important ancestors and allelic diversity in the Japanese Thoroughbred population were examined by applying the gene dropping simulation to the foals produced from 1978 to 2005. Full pedigree records traced to ancestors (base animals) born around 1890 were used for the simulation. Alleles originated from some of the historically important ancestors were found to be at risk of future extinction, although their genetic contributions to the foal population have increased during the last three decades. The proportion of surviving alleles to the total alleles assigned to the base animals was $8.0 \%$ in the foal population in 2005, suggesting that a large part of genetic variability contained in the base animals is extinct in the current population.

Key words: allele survival, allelic diversity, gene dropping simulation, genetic contribution, Thoroughbred
J. Equine Sci.

Vol. 21, No. 3

pp. 39-45, 2010
Although the current Thoroughbred population numbers more than 300,000 word-wide, all the horses share a limited gene pool in the early 18 th century [9]. In this breed, monitoring of the genetic diversity would be of an essential importance for future breeding.

In the breeding history of Thoroughbred, many prominent ancestors appeared. They genetically contribute to the current population with various degrees. Characterizing the genetic constitution in each country population by the genetic contributions of prominent ancestors would be useful for the worldwide monitoring of the genetic diversity in the whole breed. Gene dropping simulation [5] could be an effective method for this purpose. From this method, distributions of frequencies of ancestors' alleles and probabilities of allele extinction in a population under question can be estimated. Although this method was

This article was accepted June 3, 2010

*Corresponding author. e-mail: nomurat@cc.kyoto-su.ac.jp originally proposed to captive breeding of endangered wild species, the application to domestic animal populations has been proven to give useful information for evaluating and monitoring the genetic diversity [2, $3,7,8]$.

We tried to characterize the genetic constitution of a Japanese Thoroughbred population by applying the gene dropping simulation to the population. Pedigree dataset supplied from the Equine Research Institute, Japan Racing Association (JRA), was used, which was created by referring to the stud books and consisted of the pedigree of the foals produced in Japan from 1978 to 2005. Pedigree of the foals could be traced to ancestors born around 1890. These ancestors are referred to as 'base animals', and the population to as 'base population'. Average numbers of generations to the base population were 5.64 and 9.09 for the foal populations in 1978 and 2005, respectively. The number of foals in each year was given in our previous report [10]. 
Table 1. Names, birth years and birth countries of nine stallions, whose genetic contributions were assessed by gene dropping simulation

\begin{tabular}{lll}
\hline Name & Birth year & Birth country \\
\hline St. Simon & 1881 & England \\
Tourbillon & 1928 & France \\
Hyperion & 1930 & England \\
Nearco & 1935 & Italy \\
Nasrullah & 1940 & England \\
Royal Charger & 1942 & England \\
Native Dancer & 1950 & USA \\
Northern Dancer & 1961 & Canada \\
Sunday Silence & 1986 & USA \\
\hline
\end{tabular}

Genetic contributions of prominent ancestors and survival of their alleles

Nine stallions were chosen as historically important ancestors for the Japanese Thoroughbred breeding, according to Yoshizawa [11]. Their names, birth years and birth countries are listed in Table 1.

Gene dropping simulation was applied to the foal populations in 1978 and 2005. For the stallion "Sunday Silence" born in 1986, only the foal population in 2005 was analyzed. In the simulation, unique alleles were assigned to the nine stallions, and the genotypes of all descendants along the actual pedigree were generated through Monte Carlo simulation following Mendelian segregation rules. By replicating 10,000 times of this process, the distribution of frequencies of alleles from each of the stallions was estimated. Theoretically, the mean of the distribution of allele frequencies for a stallion gives the genetic contribution of the stallion to the foal population $[1,5]$. The probability of extinction of alleles originated from a given stallion was calculated as the proportion of replicates in which both alleles from the stallion had not existed in the foal population.

Figure 1 shows the distributions of allele frequencies of the nine stallions in the foal populations in 1978 and 2005. The shapes of the distributions can be classified into two typical types: One is the shape seen in "St. Simon", "Tourbillon" and "Royal Charger", in which the peak is observed at a position close to the lower boundary of allele frequency. A large part of alleles originated from these stallions have been already extinct from the foal population, or even if they are still segregating, the frequencies will be critically low. Another type of the distribution shape is observed in "Hyperion" and "Nasrullah". This type of distribution has the peak at a relatively high allele frequency, and the probability of allele extinction, i.e., the ordinate at the allele frequency of zero, is zero or close to zero. Not only the most recent stallion "Sunday Silence" but also historical stallions such as "Nasrullah" were included in this type of distribution shape, meaning that the later stallions are connected to the current population through many genealogical pathways, and their genes are surely transmitted along the pathways.

For the four stallions, "St. Simon", "Tourbillon", "Nearco" and "Royal Charger", the distributions of allele frequencies shifted to the lower boundary of allele frequencies from 1978 to 2005 , suggesting that most of the alleles carried by these stallions have been extinct from the Japanese Thoroughbred population during the past three decades. A drastic change with the opposite direction was observed in the distribution for "Northern Dancer". This reflects the fact that the active use of his progeny for breeding in Japan was in 1980s. The distribution for "Northern Dancer" in 2005 showed the peak at the allele frequency around 0.03. A peak at the same position was also observed in the distribution for "Native Dancer". Since this stallion is the maternal grandsire of "Northern Dancer", the peak is due to alleles transmitted from "Native Dancer" to "Northern Dancer". The distribution for "Native Dancer" in 2005 had another higher peak at the lower boundary of allele frequency, which is not observed in "Northern Dancer". This peak indicates that most of the genetic contribution of "Native Dancer" to the Japanese Thoroughbred population is thorough his grandson "Northern Dancer". In other words, the original contribution of "Native Dancer", that is, the frequency of allele carried by "Native Dancer" but not transmitted to "Northern Dancer", is negligibly low, although this stallion has been considered as an important contributor to the Japanese Thoroughbred population [11].

Table 2 shows the genetic contributions and the probabilities of extinction of the nine stallions' alleles in the foal populations in 1978 and 2005. A notable point is that the probability of allele extinction for some stallions such as "St. Simon" and "Royal Charger" has increased, although the genetic contributions retained an essentially same value or even showed an increase during the period from 1978 to 2005. The increased probabilities of allele extinction suggest that the lineages connecting these ancestors to the Japanese Thoroughbred population had been limited during this period, and the genes transmitted from them had 


\section{St. Simon}

1978
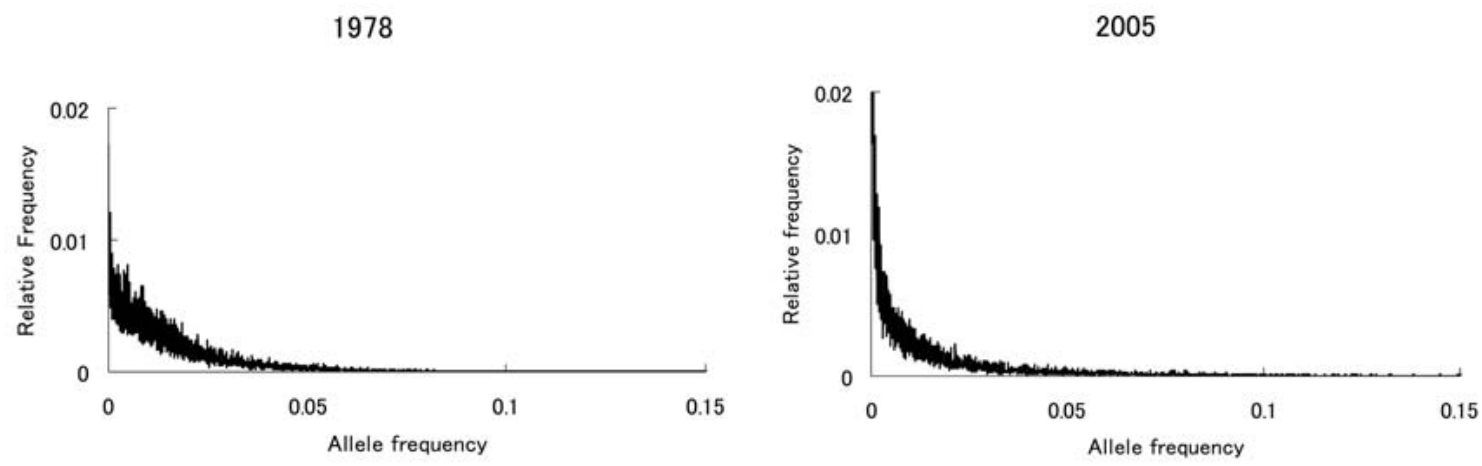

\section{Tourbillon}

1978
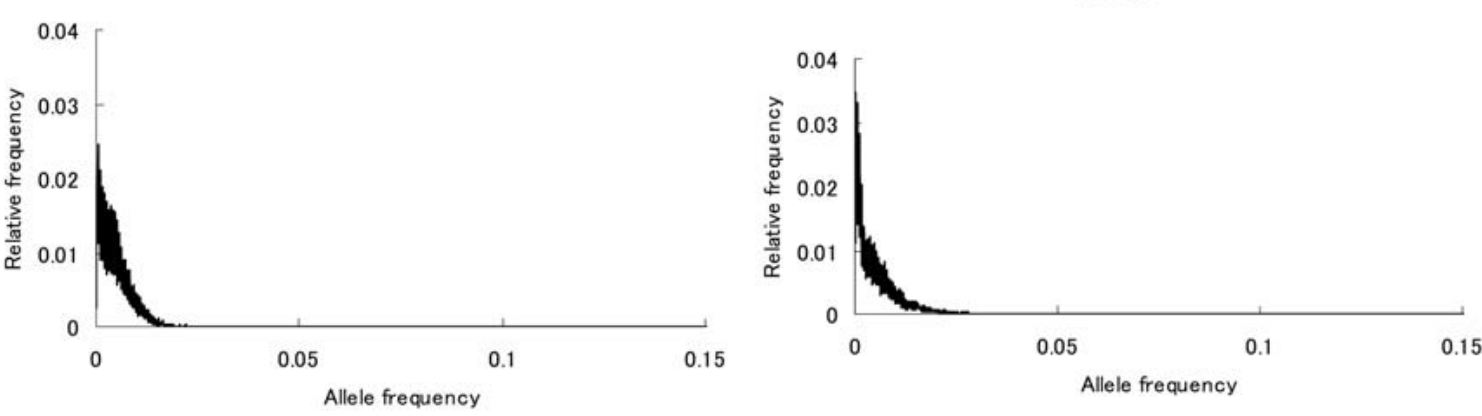

\section{Hyperion}

1978

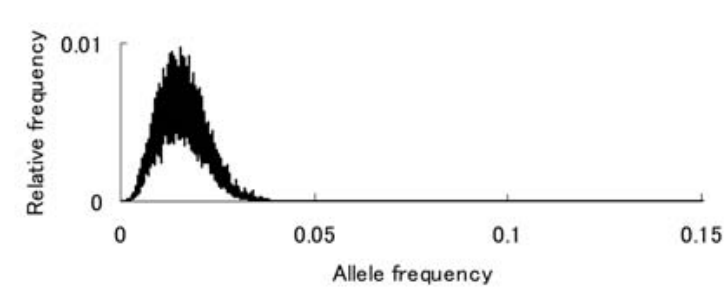

2005

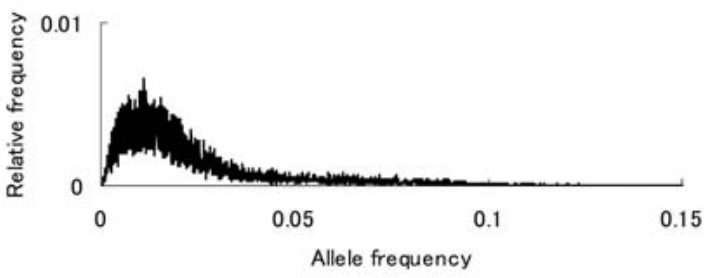

Fig. 1. Distributions of allele frequencies of nine stallions in the foal populations of the Japanese Thoroughbred in 1978 and 2006.

passed through a bottleneck of lineages. On the other hand, the probabilities of allele extinction for the three stallions, "Hyperion", "Nearco" and "Nasrullah", were estimated to be zero in 1978 and 2005, meaning that the Japanese Thoroughbred population is connected to these ancestors without sever bottleneck of lineages. 


\section{Nearco}

1978

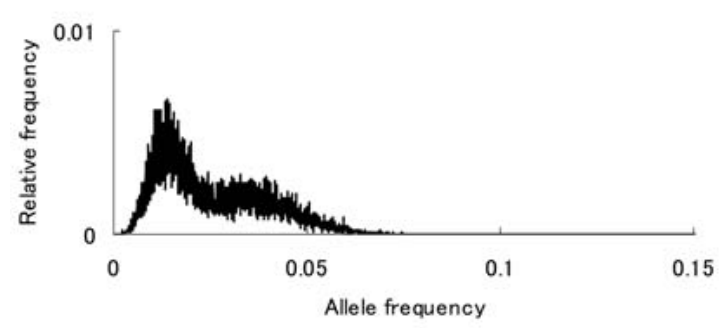

2005

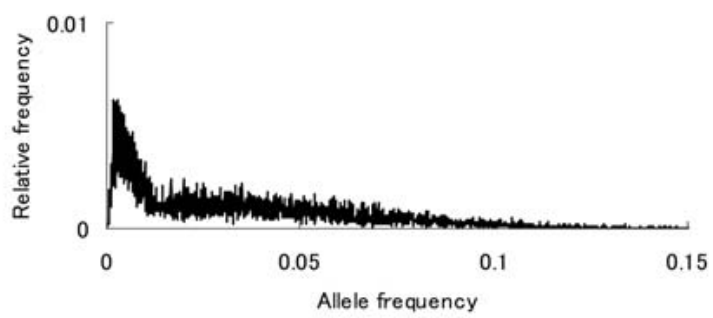

\section{Nasrullah}

1978

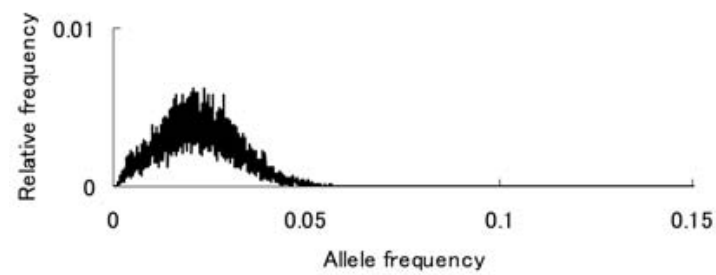

2005

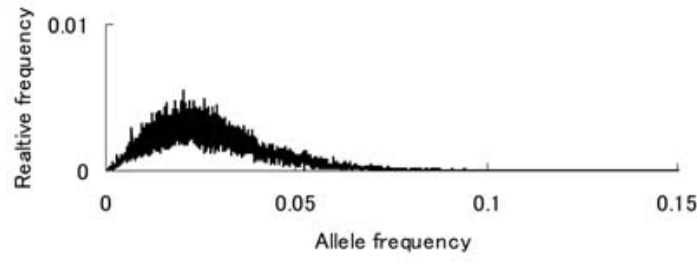

\section{Royal Charger}

1978

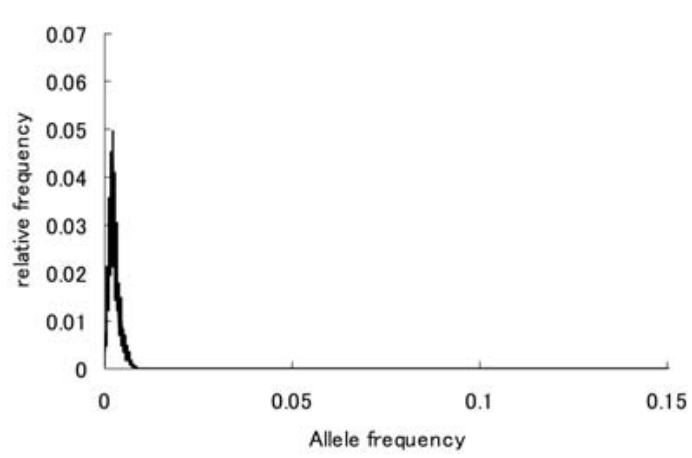

Fig. 1. continued

Allelic diversity

To assess the genetic diversity of the foal population, unique alleles were assigned to all the ancestors (base animals) in the base population, and the gene dropping simulation with 10,000 replicates was carried out for the foal population in each year. Average 


\section{Native Dancer}

1978

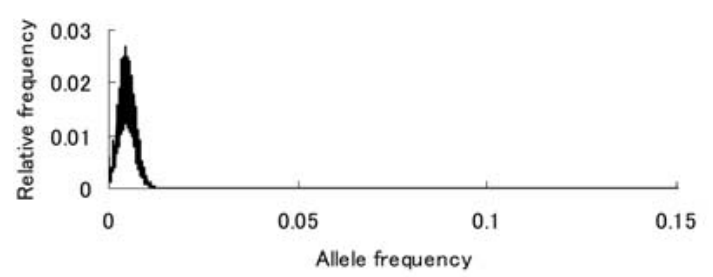

Northern Dancer

1978

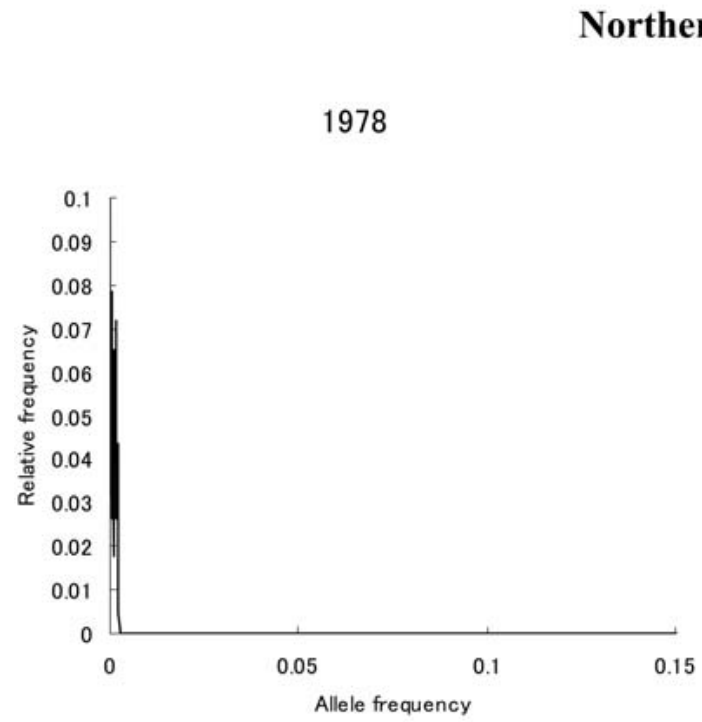

2005

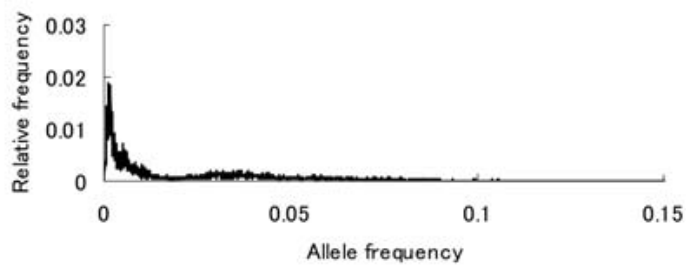

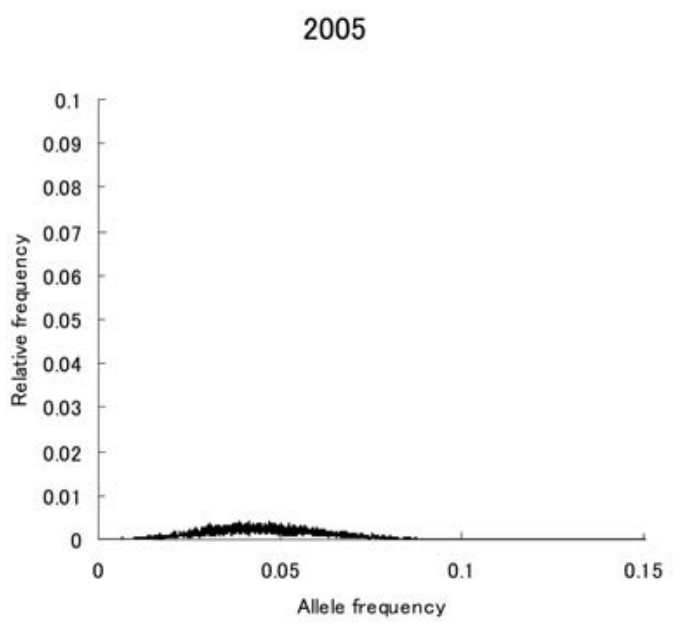

\section{Sunday Silence}

2005

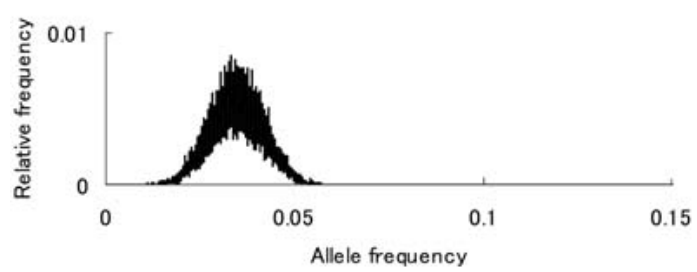

Fig. 1. continued

number of alleles surviving in the foal population was calculated for each year. The number of surviving alleles is a measure of genetic diversity relative to the base population. This number is called as 'allelic diversity' in population genetics.

Figure 2 presents the number of surviving alleles (allelic diversity) in the foal population in each year. Although total numbers of alleles assigned to the base 
Table 2. Genetic contributions and probabilities $(\operatorname{Pr}(\operatorname{lost}))$ of extinction of nine stallions' alleles in the foal populations in 1978 and 2005.

\begin{tabular}{lccccc}
\hline & \multicolumn{2}{c}{ Genetic contribution } & & \multicolumn{2}{c}{$\operatorname{Pr}($ lost $)$} \\
\cline { 2 - 3 } \cline { 5 - 6 } Stallion & 1978 & 2005 & & 1978 & 2005 \\
\hline St. Simon & 0.0143 & 0.0156 & & 0.0173 & 0.0401 \\
Tourbillon & 0.0046 & 0.0051 & & 0.0024 & 0.0110 \\
Hyperion & 0.0160 & 0.0240 & & 0 & 0 \\
Nearco & 0.0255 & 0.0351 & & 0 & 0 \\
Nasrullah & 0.0221 & 0.0279 & & 0 & 0 \\
Royal Charger & 0.0026 & 0.0081 & & 0.0004 & 0.0119 \\
Native Dancer & 0.0048 & 0.0235 & & 0.0012 & 0.0001 \\
Northern Dancer & 0.0010 & 0.0458 & & 0.0315 & 0 \\
Sunday Silence & - & 0.0347 & & - & 0 \\
\hline
\end{tabular}

1) Because this stallion was born in 1986, only the foal population in 2005 was analyzed.

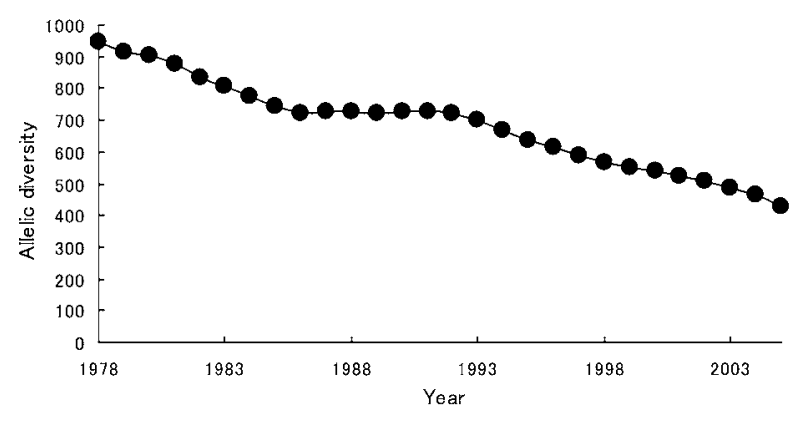

Fig. 2. The number of surviving alleles (allelic diversity) in the foal populations from 1978 to 2005 , when unique alleles are assigned to the base animals.

animals were varied among years of the foal populations, they were within range from 4,800 to 5,500 . The number of surviving alleles in the foal population in 1978 was 946.8 on average over 10,000 replicates, but the number decreased to 426.6 in 2005 , which is only $8.0 \%$ of the total number of assigned alleles to the base animals. After the initial decline in 1978-1984, there was a period in which the number of surviving alleles reached a plateau. The number again progressively declined after 1993. The later period of decline agrees with the period in which the demographic estimate of the effective population size decreased by the intensive use of a limited number of stallions for breeding [10]. These results strongly suggest that the genetic diversity in the Japanese Thoroughbred population has reduced after early 1990s. In fact, analysis of microsatellite markers has indicated a progressive decline of genetic diversity in the recent Japanese Thoroughbred population [4].
More detail pedigree analysis for the assessment of genetic diversity will be carried out in our succeeding studies.

Throughout the present study, we have limited our concern to the Japanese Thoroughbred population. Application of the similar analysis to the population in each country will clarify the geographical distribution of genetic resource in the entire breed.

\section{References}

1. Caballero, A., and Toro, M.A. 2000. Interrelations between effective population size and other pedigree tools for management of conserved populations. Genet. Res. 75: 331-343.

2. Honda, T., Nomura, T., Fukushima, M., and Mukai, F. 2002. Gene dropping analysis of founder contributions in a closed Japanese Black cattle population. Anim. Sci. J. 73: 105-111.

3. Honda, T., Nomura, T., Yamaguchi, Y., and Mukai, F. 2004. Monitoring of genetic diversity in the Japanese Black cattle population by the use of pedigree information. J. Anim. Breed. Genet. 121: 242-252.

4. Kakoi, H., Gawahara, H., and Suda, I. 2009. Evaluation of genetic diversity and usefulness of parentage verification in the recent Japanese Thoroughbred population by microsatellite DNA analysis. Equine Sci. 46: 36-48.

5. Lacy, R.C. 1989. Analysis of founder representation in pedigree: founder equivalents and founder genome equivalents. Zoo. Biol. 8: 111123.

6. MacCluer, J.W., VandeBerg, J.L., Read, B., and 
Ryder, O.A. 1986. Pedigree analysis by computer simulation. Zoo. Biol. 5: 147-160.

7. Rodriganez, J., Toro, M.A., Rodriguez, M.C., and Sillio, L. 1998. Effect of founder allele survival and inbreeding depression on litter size in a close line of Large White pigs. Anim. Sci. 67: 573-582.

8. Toro, M.A., Rodriganez, J., Sillio, L., and Rodriguez, C. 2000. Genealogical analysis of a closed herd of Black Hairless Iberian pigs. Conserv.
Biol. 14: 1483-1851.

9. Willet, P. 1991. A History of the General StudBook. Weatherbys, Northants.

10. Yamashita, J., Oki, H., Hasegawa, T., Honda, T., and Nomura, T. 2010. Demographic analysis of breeding structure in Japanese Thoroughbred population. J. Equine Sci. 21: 11-16.

11. Yoshizawa, J. 2001. Pedigree of Racing Horses. NHK Press, Tokyo. 